\title{
The role of fantasy in social media use
}

\author{
A lacanian approach to digital youth
}

Af Niels-Peder Osmundsen Hjøllund

\begin{abstract}
Hovedformålet med denne artikel er at spørge til hvordan brugen af digitale og sociale medier påvirker positioneringen af subjektet. Gennem en psykoanalytisk teoretisk ramme vil artiklen pege på transformative aspekter $i$ dannelsen af forskellige diskurser og hvordan dette påvirker unges måde at forstå information på. Artiklen peger således på, hvorledes psykoanalytiske begreber kan finde anvendelse $i$ analysen af det digitale medierum. Artiklen vil undersøge følgende spørgsmål "Hvordan påvirker brugen af digitale og sociale medier dannelsen af subjektet?" og "hvilken betydning har sociale medier og digital interfacing for det menneskelige subjekts forståelse af information?"
\end{abstract}

Artiklen vil ved brug af Jacques Lacans kommunikationsmodel give et eksempel på hvordan en psykoanalytisk tilgang kan anvendes som analytisk blik på digitale medier, information og meningsdannelse.

Niels-Peder Osmundsen Hjøllund, PhD stipendiat Det informationsvidenskabelige Akademi, Københavns Universitet qxm592@hum.ku.dk

\section{Introduction}

The contemporary generation of young people use digital technology and social media like never before. The use of social media among adolescents are wide spread and ranges from reading news, searching for information, playing games, making new friends, and staying in touch with those they already know. The diverse and multiple uses make the platforms and their users an interesting and important object of study. We are in a time where digital technology plays an important and central role throughout society and the use of different platforms can potentially give us important insights and answers into how sociality and subjectivity forms and plays out in the 21 st century. In Denmark a recent study shows that, among young people aged 16-24, 96\% use the internet on a daily or almost daily basis and $95 \%$ use social media. ${ }^{1}$ One aspect that these figures underline is the importance of the internet and social media in the lives of Danish youth. Even though social media is still predominantly a phenomenon bound to the everyday life context, the tools and platforms have been used for some years in higher education and are now beginning to gain hold further down, especially in the upper secondary school.

Discussions of prospects and problems in using social media in education have been intensified in Denmark during the last couple of years and studies have been undertaken to investigate what impact the use of these tools have on different factors such as motivation, attention, and learning outcome (E.g. 
Paulsen \& Tække, 2009/2013; Mathiasen et al., 2013/2014). Many of the studies undertaken have focused on specific use patterns and how social media can be implemented as a tool for learning. These aspects are important issues when we discuss youth and their use of digital tools and social media. However to further understand specific use patterns and the integration of social media in education we also need to study and theorize on more fundamental questions regarding the use of social media and digital technology. What consequences can the extensive use of digital tools and social media platforms be said to have on sociality, more specifically on formation of identity; and the psycho-social formation and transformation of the individual and social discourses?

To answer these questions this article will explore some aspects of a psychoanalytical theoretical framework for analysis that could point to transformational features in the formation of different discourses and how these influence the way young people appropriate information. This article and its theoretical framework is part of a larger research project which examines digital youth and the use of social media in everyday life and education. The larger project operates in the field of information literacy and digital youth and aims at developing a theoretical frame to further our understanding of the concept of information through an examination youth's appropriation and dissemination of information.

The theoretical approach to subjectivity, social media, information and information literacies will be grounded in the psychoanalytical theory of subjectivity and subject positioning, as developed by Jacques Lacan (Lacan, 1988, 1998). Lacan proposes a model for how the communication and the subject positions can be analyzed by use of a model of discourse. Here, the discourses of the master, the hysteric, and the university play important roles as means of understanding how the subject is situated in communicative practices outside of the clinical setting. In this article, I will take the hysterical discourse into consideration and use it as an example of how psychoanalysis and the lacanian approach can be used as an analytical tool for how interfacing and fantasy situate the subject in the use of social media.

The questions I will try to answer in this article are, "How does social media use and technological in- terfacing affect the formation of the subject?" And "What consequences does the use of social media and the technological interfacing have for how we as human subjects appropriate and disseminate information?"

\section{Some introductory remarks on lacanian subjec- tivity}

One of the first things that we need to have in mind when working with the psychoanalytical approach (as also noted by Day, 2011) is that this approach reconceptualises some of the notions of objects and subjects in a way so that the strong divide between the two are to some extend erased or more precisely intertwined. This intertwined nature of object and subject can be further exemplified and explained via the lacanian model of ontology. These ontological concepts and their relation will be briefly presented here and used throughout this article as a basis for thinking about and analysing social media, information, and dissemination of information.

In psychoanalysis, and also in Lacan's approach to subjectivity, the fantasy object plays an important role in the constitution of the subject of desire. The formation of the subject via part-objects stems from Lacan's work on the development of the child via the mirror stage, where the child captures objects and other persons as part of their own image or imago. This play of internalising persons or objects also, but not fully, as images of our own ego is important as this is what in lacanian terms is named the imaginary order. Thus the imaginary could be termed the order or place of imagined objects. These objects are fantasy objects or part-objects because they are exactly not "real" objects, but objects that are substitutions of what Freudian theory would name primary objects, for example the breast of the mother. The breast is as such the object par se as it is that which, in our earliest childhood, fulfils our needs. This object is then taken away from us and in trying to reach fulfilment of our primal needs we use phantasmatic staged part-objects or fantasy objects to reach that fulfilment. Lacan's description of the fantasy object in his explanation of the oral drive can be illustrative when explaining the idea of both the imaginary and also the idea of fantasy and phantasmatic framing. In his discussion he points out that "it is not introduced as the original food, it is introduced from the fact that no food will ever satisfy the oral drive, except by 
circumventing the eternally lacking object" (Lacan, 1998, p.180). The imaginary and fantasy works as a medium that supports our construction of reality by providing satisfaction without actually attaining fulfilment of "natural" needs.

Furthermore, what constitutes the subject of desire is its place in the symbolic order. The symbolic being the place or more specifically the order of public language and also the order of signification. This symbolic order is, in Lacan's theory, a sociocultural 'place' ruled by the law of the Other. The Other can be seen as the position that guarantees the functioning of the symbolic. To Lacan, language is never a personal phenomenon but always a public one, as the subject is always already given to the symbolic via the language of the Other (Day, 2011).

It is important to understand that, although Lacan distinguishes between imaginary and symbolic, it is hard to pinpoint exactly where they diverge. But it might be a good point to see language as bound in the symbolic order - as it is through language that we as subjects symbolize and signify reality - and to see the imaginary as where we break the law of the symbolic and fantasize about our ability to go beyond the symbolic constraints of reality (Rösing, 2005, Day, 2011). So, reality for the human subject is in this way always an interplay between the imaginary and the symbolic: a crisscrossing of symbolic signs and imaginary images; a mixture or split between the symbolic order of the Other "alterity that lies outside and prior to the subject" (Day, 2011, p.82) and the imaginary order or reflection of the ego that lies after subjectivation has occurred.

\section{Fantasy, social media, and literacies}

Fantasy can be understood as having two main functions. One is to give the human subject the possibility to surpass the structuring of our reality in the symbolic order; meaning the ability to imagine about realities beyond reality itself and in that sense fantasy is a part of the imaginary order. This can also be named the conscious fantasy, or the creative imagining of the subject. These fantasies are not unimportant but they do not have the same structuring role as the second and unconscious function of fantasy. In the second sense, fantasy is what, as explained in the previous section, rules the formation of the desirable object. Thus, fantasy is a medium supporting our re- ality by making it an attractive and engaging process. André Nusselder puts it this way

"[...]The fantasy object is[...] either an appearance in which the subject creatively represents the real, or an illusion or imaginary lure in which we disregard the element of subjectivation and fall into the trap of objectification: taking representation for real and ignoring desire's hide-and-seek universe." (Nusselder, 2009, p. 101)

As such there is no meaning or sense in the individual, but it is constituted in the exchange of symbols in and through language. Our understanding through the symbolic order is not a representation of the reality we inhabit but of the symbolic order itself. Our language of and in this order is structures of reality and not reality itself.

In structuring reality and thereby also meaningful dissemination of information we unconsciously use fantasy as a co-structuring force. This means that fantasy is not the opposite of reality itself but also the libidinal and unconscious motivation for our structuring of the symbolic functioning of reality.

The roles and functions of the imaginary and how fantasy co-structures both desire and the subjectiveobjective space of our interfacing with technology are in this view important aspects of how we can understand subjectivity and also what it means to be information literate in the 21 st century. We need to look at how the fragmented representation in form of images, sound bites, video clips, and in the end 0s and $1 \mathrm{~s}$ could correspond to the fragmented characteristic of the psychoanalytic theory of subjectivity.

New media can be said to position the subject in a certain way towards the reality we experience. It functions as a window to the world or as a frame for how we experience reality. This window or frame metaphor can be useful in describing how the phantasmatic formation provides us with either a part-picture of reality enabling us to see reality or becomes a mirror-image that does nothing but mirror our imagined ego. In this way, cyberspace would not really be worth the effort or time if it was not for 'our (unconsciously) positing "something" in the impressions that we get from the other on the screen.'

(Nusselder, 2009, p.13) 
As subjects of desire we use new media (e.g. Facebook) as a window or frame for deciding and decoding the characteristics of our self and others. In doing so we deposit 'something' in the experience we get. We are then in a situation where Facebook and information technology can help uncover our relation to desire and the enjoyment that, in the end, is the fulfillment of desire. On the other hand, the imaginary play of our interfacing with social media through the work of fantasy can cut us off from the 'hide and seek' of desire. Placing something in the gaps of representation gives a sense of awareness of how others are or how the information we've found fits with previous experiences. But this sensation is also bound in our own phantasmatic framing of the part-picture of reality that is presented to us. Thereby information seeking and, as a consequence, being information literate has a lot to do with the phantasmatic framing of the symbolic signifiers that is the exchange of information for the human subject.

I will now move on to present the lacanian model of discourse and give an example of how it can be used to analyse and show how the interfacing with technology can act as a force of critical acknowledgement - meaning that it can help the subject understand the partial view of reality that is the consequence of being a subject of desire. The analysis can on the other hand also show that the use of social media as an information source can create the lure of taking representation as objective truth and thereby leading the subject to a disregard of subjectivation and "taking representation for real and ignoring desire's hide-and-seek universe."(Nusselder, 2009, p.101)

\section{The lacanian model of discourse}

The lacanian model of discourse $\mathrm{e}^{2}$ has as its outset four different positions. These four positions are the $\$$ (the split subject) $^{3}$, the petit objet a (the object of desire $)^{4}, \mathrm{~S}_{1}$ and $\mathrm{S}_{2}$.

$\mathrm{S}_{1}$ is the master signifier; the signifier that sets the discourse. This signifier is the authority, but as such this authority is only grounded in itself. $\mathrm{S}_{2}$ is the other signifier that according to the logic of structuralism is necessary to have a first signifier. These signifiers exist only in relation to each other and are therefore dependent on each other.
'If $S_{1}$ is the master then $S_{2}$ is the slave. If $S_{1}$ is the teacher then $S_{2}$ is the student [...] The Master is always master for another. The Master is dependent on another to be Master in the first place.'(Rösing, 2005, p.116 my translation)

Basically Lacan's model of discourse looks as follows:

$\frac{\text { agent } \rightarrow \text { other }^{5}}{\text { truth } / / \text { product }^{-}}$

The agent is the position from where speaking takes place. The other is the position that is spoken to. The product is what is produced in the act of speaking. The truth is the unconscious drive behind the communication process that remains hidden to the subject that speaks. These positions can be understood on multiple levels both as abstract entities, interpersonal entities and as elements in one person. For pedagogical reasons I will explain the position on a personal level.

The hysterical discourse that will be used as an analytical example enables us to point to issues of affectual processes and positioning when a given subject searches for information on other subjects via social media like Facebook, for instance. The model is as follows.

$\frac{\$ \rightarrow \mathrm{S}_{1}}{a / / \mathrm{S}_{2}}$

In the hysterical discourse the split subject(\$) poses or speaks to the position of the master; Facebook $\left(\mathrm{S}_{1}\right)$. Being in the position of the master Facebook is supposed to be able to tell the subject who the others are and through this also who we are ourselves. In this process what is produced is knowledge about the subject $\left(\mathrm{S}_{2}\right)$. But what remains hidden is the truth about the subjects own desire, that the master will never be able to tell the subject what the subjects truth is. The fact that the desire to know or reach fulfillment (see the section on lacanian subjectivity) through the petit objet a is impossible is in this case hidden or barred.

So what the subject gets when it places Facebook in the position of the master is a partial picture of the other person and at the same time a partial picture of itself. At best the subject would find out how the 
other person 'poses'. Thereby what is seen through the information from Facebook is how the others relate to their Other. What arises from this is a sort of double imaginary where the subject through its own phantasmatic framing of how others pose, experiences how their phantasmatic image relates to the master and thereby experiences an imagined picture of their own posing for the Other.

One could argue that Facebook becomes the framework for how it is possible to pose. The partial and incomplete image becomes an ideal image of how the individual is, and can thereby be said to support the phantasmatic self-images of the ego. In the analysis of Facebook via the hysterical discourse, we can begin to grasp how our digital tools both provide us with readily available phantasmatic frameworks and also, more often than not, take on the role as the one who knows, it can be said to 'know for us'. Thereby social media platforms like Facebook, will play an important role in the possible ways subjectivity can be formed and thereby also play a role in the formation of identity and social discourses.

It is at the same time important to note that the hysterical discourse is also the discourse of critical acknowledgement and therefore the positioning of social media, in this case Facebook, as the master can also provide leverage for the breakdown of the understanding of oneself as a coherent subject without doubts and contradictions. So, there is a double binding in the use of Facebook and this double binding can be articulated via the lacanian model of discourse.

In the next part I will concentrate on the concept of information and how information and digital tools interface with human subjectivity. I will look at how the meaningful dissemination of information to a great extend stem from our interfacing with technology and how the algorithms of social media software to a certain degree structures the dissemination of information and thereby also affects the formation of the subject. This will help show why the concept of fantasy is important in the understanding of our use of digital technology and social media and how psychoanalysis is actually a very useful tool for analysing this use.

\section{Information and the use of social media}

In the approach taken here, I understand the concept of information as being a sociocultural phenomenon that, so to speak, resides in the social domain and thereby also in the symbolic order of signifiers.

I understand information as a sign that points to an object and maybe more significantly, a sign that again points to another sign and so on, leading to a chain of signifiers.

What could be termed the objective view on information predominantly understands information as a thing or signal (Parker, 1974; Shannon \& Weaver, $1949 / 1964)$ existing independently from the meaning-making process of the subject. The subjective view on information holds that information more has the quality of a sign that relates an object to meaning depending on social and cultural contexts (Buckland, 1991; Hjørland, 2007; Qvortrup, 1993). As Joseph A. Goguen reminds us 'An item of information is an interpretation of a configuration of signs for which members of some social group are accountable.' (Goguen, 1997, p.4). Goguen's suggestion implies that information is also dependent on context and that the dissemination and meaning-making process of the subject necessarily entail an interpretation of signs. Following Lacan the idea of the structuring of signifiers entails that the symbolic sign system has the structure of language. This means that the subject interpreting the signs is always an infinite process and that the meaning and definition of one signifier is only given by its relation to other signifiers. ${ }^{6}$

In the context of information as a sociocultural and subjective phenomenon, the meaning of information can be seen as shaped, on the one hand, through the interfacing with artefacts and, on the other, as a symbolic semiotic process taken on by the individual but co-determined by social discourse.

Using tools, in this case social media, to search for information in everyday life or to study curricula in high school is a process in which the user and the tool shape and transform each other.

Given this view, information and to be information literate is something that is both located in the human subject and in the context of the tool which is 
utilized in the search and use of information. As William Mitchell puts it:

\begin{abstract}
"Tools are made to accomplish our purposes, and in this sense they represent desires and intentions. We make our tools and tools make us: by taking up particular tools we accede our desires and we manifest intentions." (Mitchell, 1992, p.59)
\end{abstract}

Social media are invested with some characteristics of human subjectivity. To make sense of the information given to us through the computer we need something to give us a notion of a what- and how-to with information. We need a screen or a window for our perception of the information. As Andre Nusselder suggests:

"We should avoid considering cyberspace as an objective fact or objective information. It is a product of human imagination, in which we use known metaphors for a new domain of information and communication." (Nusselder, 2009, p.17)

His suggestion points to the idea that social media and cyberspace does not exist as independent or neutral spaces providing us with objective facts or objective information. Social media spaces are constructs that make us do and see things in ways we are not always conscious of. The software and social media are as such not coincidental constructs, but to great extent products of our combined social imagination. By this I mean that because social media is not an objective fact, the subjects imaginative and symbolic position plays an important role in defining the boundaries of what is at all possible to do with social media.

The approach of considering media and information as something that is not objective as something that is also bound to the imaginary order of the subject, and that our use of particular tools as manifesting intentions points to a view of technology that is noninstrumental but focused on the transformative powers of the human-technological relationship. Understanding technology, and in this case social media, as volition (Nusselder, 2009) in which it is related to aims, intentions, desires, and choices of humans as the "users" of technology could actually provide an opportunity to understand the different aims of different uses in different contexts. So the volition of technology has to do with the will to act and thereby a lot to do with desire and with the functioning of the unconscious. Here fantasy works as a structuring force that is active in our engagement with tools and in our drive to overcome gaps in the signifiers and the signifying chain of the symbolic order.

So what about the data making up the information available to us on the screen?

The basic notion of mediation through the Other, or what could be called alienation, is crucial here. The big Other as the reservoir of the signifying elements we use to construct linguistic representations and the locus where speaking takes place is in relation to social media and digital tools also present and maybe even present to a larger extend and stronger degree than ever before:

"...The big Other has to be there, more powerful than ever in the guise of cyberspace itself, this directly universalized form of sociality which enables us to be connected with the entire world while sitting alone in front of a screen." (Žižek, 2008, p.34)

In our use of digital tools and especially social media the concept of fantasy is useful and important, as it is our fantasy or our phantasmatic drive that co-structures our sense-making of information as well as our making sense of technology.

When we make use of for example social networking sites, our production of meaning is to some extend bound in the way the medium structures our understanding of the way the information is given to us. The way strings of $0 \mathrm{~s}$ and $1 \mathrm{~s}$ are programmed, in for example Facebook, is in a certain way meant to represent certain aspects of all the details making up the subject behind the screen. This way of representing via use of an avatar, so to speak, makes for a certain understanding of the information given to us. Not that the algorithms behind are controlling all parts of that representation, but it is to a large extend chosen and sorted by the algorithms running Facebook. Thereby our connection with the interface and our libidinal phantasmatic investment in the information opens up for the interpretation of cyberspace as the big Other.

So as human subjects we can be said to exist in "the in-between", in the middle, or in media. An assump- 
tion that can also be found resonated in Mark Deuze et al:

"If anything, the logic of media must be seen as dissolving the distinctions drawn all too easy between humans and machines." (Deuze et al., 2012)

The imaginary plays an important role as it is fantasy or more precisely our phantasmatic framing of desire that to a large extend structures our interfacing with tools, in this case social media, and also how we interpret the information given to us by the screen. Transfer of meaning through mediated practices can be seen as a virtualization of self and medium, where information is interpreted through the imagination of the subject and brought onto the social stage as something in between stages; as a 'negotiation' between our conscious and unconscious interpretation of reality. Or put in another way, production of meaning and thereby dissemination of information relies on both social discursive factors and also on the imaginary fantasies of the subject that interprets that information. In this sense the subject is both constructed in discourse, but in lacanian theory the subject also stands outside discourse as it is basically impossible for a given discourse to capture and completely signify the subject. This builds on both Lacan's idea of the subject of desire, but also on his coupling with cybernetics as the workings of language and thereby the signifying chain of the symbolic can be said to work on presence and absence, or 0's and 1's. (e.g. Lacan 1988, Lacan 2007)

\section{Regimes of information and attention}

By taking the lacanian approach and considering what role the symbolic and imaginary meaning-making of the subject plays when interacting with social media, I have in this article tried to show how theoretical concepts from psychoanalysis can be utilized in the study of digital youth and social media.

Building on the idea of subjective-objective space, we can now look at cyberspace and thereby also social media as being both an important information source and tool of subjectivation in contemporary life. It is to a large degree through the use of social media that friendships and social relations are formed and maintained among adolescents, or what we could term digital youth. But understanding, interpreting, and generating meaningful signs in the context of social media can prove difficult as one characteristic of social network sites is the collapse of context (Boyd, 2011) making it difficult to decode which context and thereby also which social discourse the individual is actually situated in at any given moment, thereby making it difficult to know what Other is at play.

When discussing literacies we might actually need to move beyond the sometimes limited view of how specific social discourses situates literacy and use of tools, and think in transformational and discourse breaking structures as a consequence of the collapsing context. The collapses that occur do so largely due to exponential growth in the use of social and mobile media in almost every facet of life among digital youth. In order to understand the struggles of attention and how these affect the literacy practices and also how the literacy practices affect what is deemed worth giving attention to, we need to investigate the criss-crossing of different contexts and what kind of signification and subject positioning is meaningful in one, the other, or all contexts. The psychoanalytical approach to research in information, digital, and media literacies as well as literacy practices can prove useful in investigating the criss-crossing of the sociocultural and the discursive approaches to information literacy. (Limberg et al., 2012)

Using the psychoanalytical approach to subjectivity and the concept of fantasy could actually provide us with an opportunity to analyse and study the way specific social discourses are structurally bound to that which escapes those discourses.Furthermore I might enable us to take into account the broad historical practices because language as the carrier of signs and signifiers has both the mark of specific context but also the mark of broader symbolic signification.

\section{Concluding remarks}

As new media becomes more and more embedded in our lives it raises a series of questions on knowledge, sociability, information, and the agency of humans and non-humans. Social and mobile media play many roles as they are used to make new friends, search for information, gain knowledge etc. Therefore, the complexity of information and of human interaction grows. Through the use of different social network sites, online encyclopedias, and mobile de- 
vices we no longer live with media and information but in media and information. (Deuze et al., 2012).

I have in this article argued that in studying youth and social media and in understanding what constitutes our relation to these, and thereby also the literacies needed to decipher information mediated through them, we need to look at how we interface with the digital technology. I argue that both the psychoanalytical theory on subjectivity and its conceptualization of fantasy could provide us with a very useful lens that can help articulate the subjective-objective functioning of both humans and tools.

With the growing use of social media we need to look at, analyse, and theorize on fundamental issues of how the use of these media discursively position humans and non-humans.

Communication and sense making through mediated practices can be seen as a virtualization of self where information is externalized through the imagination of the subject and brought onto the social stage as something in between stages; information as a social negotiation between the sender and the receiver. In this negotiation fantasy plays a role in how the subject of desire along with new media structures and forms the relation between information and knowledge. New media takes on the role as the one who knows; it can be said to 'know for us'. Therefore it can possibly act as a co-structuring force in the relation between subject and world and therefore also inter-subjectively between teacher and student. The lacanian and psychoanalytical approach gives us the opportunity to think about and study fundamental issues in the use of social media and digital tools. Thereby it gives us a theoretical framework, when studying the transformation of discourses. This theoretical framework can broaden our view and open up for new understandings of how information literacies work and play out.

\section{Further Perspectives and the larger research pro- ject}

The lacanian idea of subjectivity and the role of fantasy in the use of social media pinpoints the difficulties in decoding the shifting and collapsing contexts; for whom to pose, what big Other to pose for, affects how to approach the in-between of everyday-life and educational life. This is especially important when two or more social discourses collide and coincide as could be, and most probably will be, the case when social media is introduced in education as a tool for learning. As Paulsen \& Tække has pointed out in their research on the use of Twitter in upper secondary school, one issue that plays an enormous role in the contemporary schools is the issue of attention and the struggle between 'correct' and 'incorrect' use of new media and especially social media in the classroom (Paulsen \& Tække, 2009, 2013, 2013b). The approaches in the educational context range from a ban policy at one end, where social and mobile media are banned, to a laissez-faire approach at the other end. In the view of Paulsen \& Tække, this results in different problems at both ends of the scale. At one end there is a struggle between visibility and invisibility of usage and at the other end there is no attention to the usage at all. This means that at either end of the scale we have a struggle of both correct/incorrect usage and of attention, in the sense that attention to curricula are not necessarily in the foreground in adolescent use of social media. This can in turn originate from the collapsing of the contexts. Social networks open up the classroom to communication and information from the outside world. The open-ended spatiality of cyberspace can also open up the physical space of the classroom and to a greater extent than ever before create a struggle of attention between the outside and inside of the educational context and thereby collapsing the physical boundaries of educational situations.

\section{Notes}

1. http://www.dst.dk/pukora/epub/upload/18685/ itanv.pdf fig. 8 \& 12

2. The lacanian model of discourse has four discourses; the master, the university, the hysterical, and the analytical. Opposed to for example Foucault's discourses that are also defined by their contents, Lacan does not define discourses from their contents, but from their form. It is not what is said but from what position it is said. (Rösing, 2005) The reason that the analytic discourse is not considered in this article is that it is coupled specifically with the analytical situation, i.e. the clinic.

3. When humans are inscribed in the symbolic order we are thrown under this order by the struc- 
tures of the symbolic; the chain of signifiers. In our subjection to the symbolic order we become split. This split is brought on by castration whereby we are inscribed in the symbolic order as subjects with desire.

4. The petit objet $\mathrm{a}$ is in lacanian terms the object of desire or the part object. This object is as such never fulfilled or reached as it is the petit objet a that is the cause of desire in the first place.

5. Model taken from Rösing, 2005

6. In his development of the chain of signifiers Lacan was influenced by saussurean linguistics and the idea that one sign only has meaning as being something different than another sign. The sign in itself does not contain meaning.

\section{References}

Boyd, D (2011). Social Network Sites as Networked Publics: Affordances, Dynamics, and Implications. In: Papacharissi, Z (Eds.), A Networked Self-Identity, community, and Culture on Social Network Sites. New York: Routledge, (p. 39-59).

Buckland, M (1991). Information and information systems. New York: Greenwood Press.

Day, RE (2011). Death of the User: Reconceptualizing Subjects, Objects, and Their Relations. Journal of the American Society for Information Science and Technology, 62(1) (p.78-88).

Deuze, M et. al. (2012). A Life Lived in Media. In DHQ: Digital Humanities Quarterly Vol. 6 nr. 1 2012.

Goguen, JA (1997). Towards a Social, Ethical Theory of Information. In Social Science Research, Technical Systems and Cooperative Work: Beyond the Great Divide, edited by Geoffrey Bowker, Les Gasser, Leigh Star and William Turner, Erlbaum pp. $27-56$.

Hjørland, B (2007). Information: Objective or subjective/situational? Journal of the American Society for Information Science and Technology. 57(10), pp. 1448-1456.
Lacan, J \& Miller, JA (Ed.) (1988). The Seminar of Jacques Lacan, Book II: The ego in Freud's theory and in the teqnique of psychoanalysis 1954-1955.(S. Tomaselli, Trans.) Cambridge: Cambridge University Press.

Lacan, J \& Miller, JA (Ed.) (1998). The Seminar of Jacques Lacan, Book XI: The Four Fundamental Concepts of Psychoanalysis. (A. Sheridan, Trans.) New York: Norton.

Lacan, J (2007). Ecrits: The first complete edition in english (B. Fink, Trans.) New York \& London: Norton.

Limberg, L, Sundin, O \& Talja, S (2012). Three Theoretical Perspectives on Information Literacy. Human IT 11.2, pp. 93-130.

Mitchell, WJ (1992). The Reconfigured Eye. Visual Truth in the Post-Photographic Era. Cambridge, Mass.: MIT Press.

Nusselder, A (2009). Interface Fantasy - A Lacanian Cyborg Ontology. Massachusetts Institute of Technology.

Parker, EB (1974). Information and society. In: C.A. Cuadra \& M.J. Bates (Eds.), Library and information service needs of the nation: proceedings of a Conference on the Needs of Occupational, Ethnic and other Groups in the United States, pp. 9-50. Washington, DC: U.S.G.P.O.

Paulsen, M \& Tække, J (2009). Om den uformelle (mis)brug af medier i det formelle uddannelsessystem. MedieKultur, vol. 46 pp. 56-72.

Paulsen, M \& Tække, J (2013). Social Media and Teaching: - Education in the new media environment. Paper presented at nordmedia 2013: Defending Democracy.

Paulsen, M \& Tække, J (2013b). Sociale medier I gymnasiet - mellem forbud og ligegyldighed. Forlaget UP København.

Qvortrup, L (1993). The controversy over the concept of information. An overview and a selected and annotated bibliography. Cybernetics \& Human Knowing 1(4), pp. 3-24. 
Rosing, LM. Psykoanalyse - Lacans formalisering af Freud. Esmark, A, Laustsen, CB \& Andersen, NA(Eds.), Poststrukturalistiske Analysestrategier. Frederiksberg: Roskilde Universitetsforlag, pp. 97126.
Shannon, CE \& Weaver, W (1949/1964). The Mathematical Theory of Communication. Urbana: University of Illinois Press, 1964. (Original:1949).

Žižek, S (2008) In defence of lost causes Verso. 